\title{
CONHECIMENTO ESCOLAR EM QUÍMICA - PROCESSO DE MEDIAÇÃO DIDÁTICA DA CIÊNCIA ${ }^{1}$
}

\author{
Alice Ribeiro Casimiro Lopes \\ Escola Técnica Federal de Química - R. Senador Furtado, 121/125 - Maracanã - 20270-021 - Rio de Janeiro - RJ \\ Faculdade de Educação da Universidade do Estado do Rio de Janeiro
}

Recebido em 8/11/96; aceito em 27/1/97

\begin{abstract}
SCHOOL KNOWLEDGE IN CHEMISTRY - THE PROCESS OF DIDACTIC MEDIATION IN SCIENCE. The aim of this article is to present a contribution of the school knowledge research to Chemistry Teaching. The object of research is school knowledge on physical sciences, considering the existence of a rupture between scientific knowledge and everyday knowledge. The differences between analogies and metaphors and the process of didactic mediation were thoroughly examined. The conclusion is that the process of didactic mediation is built on their own cognitive configurations, which not always make public the private scientific knowledge to certain social groups.
\end{abstract}

Keywords: school knowledge; didactic mediation; metaphor.

\section{INTRODUÇÃO}

O significante crescimento quantitativo das pesquisas em Ensino de Ciências no país na década de $80^{2}$ tem gerado a necessidade de maior diversificação e aprofundamento das pesquisas na área, o que efetivamente pode ser constatado nos trabalhos da década de 90 . Especialmente no que se refere às pesquisas em Ensino de Química, podemos constatar esse fato a partir de uma análise dos trabalhos apresentados recentemente no VIII ENEQ/VIII ECODECQ ${ }^{3}$.

Esse quadro confirma a posição que temos defendido quanto à necessidade de pesquisadores em Ensino de Ciências associarem análises com enfoque central na sala de aula, que priorizam aspectos metodológicos do ensino, e análises educacionais em seu sentido mais amplo, capazes de elaborar teorias nos campos sociológico e epistemológico. É fundamental, para o desenvolvimento de nossas pesquisas, que não desconsideremos contribuições de outros campos da Educação, especialmente os campos de Currículo e Didática, articuladores de férteis análises sobre o conhecimento escolar. Assim como devemos estar prontos a dialogar com a Filosofia, notadamente a Epistemologia, e a Sociologia. Desta forma, poderemos produzir a dialetização entre o mais específico - a sala de aula - e o mais geral - contexto educacional como um todo e a problemática do conhecimento.

Neste artigo, procuramos seguir esta direção. Nosso objeto de pesquisa é o conhecimento escolar nas ciências físicas, com vistas a contribuir para as pesquisas em Ensino de Química a partir de contribuições das pesquisas em Currículo e Didática.

Por conseguinte, inicialmente abordamos a perspectiva de constituição de um conhecimento propriamente escolar, através da análise da noção de transposição didática. Em seguida, defendemos a utilização do termo mediação ao invés do termo transposição para os processos de apropriação do conhecimento científico pela escola e analisamos este processo na Química. Como um dos aspectos centrais da mediação didática é a construção de metáforas e analogias na ciência e no ensino de ciências, procuramos analisar esta questão no último tópico. As conclusões deste artigo se dirigem para a perspectiva de que o conhecimento escolar é uma instância de conhecimento própria, processo de (re)construção do conhecimento científico. Porém, defendemos que o conhecimento escolar não deve ser constituído como uma deturpação do conhecimento científico, pelo uso excessivo de metáforas e analogias, capazes de promover o mascaramento da ruptura entre conhecimento comum e conhecimento científico.

\section{CONHECIMENTO ESCOLAR E TRANSPOSIÇÃO DIDÁTICA}

A perspectiva de constituição de um conhecimento propriamente escolar surge mais precisamente com a noção de transposição didática. Segundo Forquin ${ }^{4}$, esta noção foi enunciada pela primeira vez por Verret em sua tese Le temps des études, defendida em 1975, na França. Ela tem por base a compreensão de que a educação escolar não se limita a fazer uma seleção entre o que há disponível da cultura num dado momento histórico, mas igualmente tem por função tornar os saberes selecionados efetivamente transmissíveis e assimiláveis. Para isso, exige-se um exaustivo trabalho de reorganização, de reestruturação ou de transposição didática. A partir deste processo, teríamos a emergência de configurações cognitivas tipicamente escolares, compondo uma cultura escolar sui generis, com marcas capazes de transcenderem os limites da escola.

Posteriormente, Chevallard e Johsua ${ }^{5}$ analisaram a questão da transposição didática no âmbito do ensino de Matemática. Estes autores examinam as transformações sofridas pela noção matemática de distância entre o momento de sua elaboração por Fréchet, em 1906, e o momento de sua introdução nos programas de geometria franceses, em 1971. Originalmente, com Fréchet, a noção de distância na Matemática traduz a idéia de semelhança - a distância entre dois pontos representados mede uma semelhança entre objetos representados. Trata-se de uma noção elaborada com o intuito de se entenderem os sistemas não-lineares. A partir do processo de apropriação pelo sistema escolar, transforma-se em noção de geometria da reta, esvaziando-se da noção inicial.

Os autores partem do conhecimento matemático, tal qual é produzido na academia, e analisam sua penetração no que eles denominam noosfera: círculos intermediários entre a pesquisa e o ensino. Esses círculos intermediários são integrados ao sistema didático propriamente dito - professor, aluno, conhecimento escolar - e compõem um sistema didático mais amplo. Constituem o lugar onde ocorrem, ao mesmo tempo, os conflitos e as transações pelos quais se exprime e se realiza a articulação entre o sistema e seu ambiente. A noosfera se compõe de toda uma gama de elementos, que vão desde o professor que se contenta em assistir às reuniões da Secretaria, daquele que freqüenta um centro de ciências, passando pelo militante ativo de uma associação de classe, chegando até o pesquisador conhecido, o administrador e os membros de sociedades científicas ${ }^{6}$. Como resumem Chevallard e Johsua, a noosfera contém todos os que pensam os conteúdos de ensino. 
A análise destes autores aborda a transposição didática ao nível da noosfera e ao nível interno da escola. Suas conclusões mostram como um elemento do conhecimento científico, quando deslocado das questões que ele permite resolver e dos conceitos com os quais constitui uma rede relacional, tem sua natureza fortemente modificada. Trata-se de uma despersonalização e de uma descontemporalização dos conceitos, quando se tornam objetos de ensino. Desta forma, o saber ensinado aparece como um saber sem produtor, sem origem, sem lugar, transcendente ao tempo. Por isso, não é sem motivos que os livros didáticos, componentes essenciais da noosfera, omitem referências bibliográficas e históricas.

Esses fatos garantiriam, assim, segundo Astolfi e Develay ${ }^{7}$, a constituição de uma epistemologia escolar. Não se trata apenas de uma defasagem entre o que se ensina na escola e o conhecimento científico do ponto de vista temporal, ou seja, a maior ou menor atualidade do que se ensina, ainda que pareça fazer parte da estrutura mesma do conhecimento escolar essa defasagem. $\mathrm{O}$ maior problema em questão é a forma de apropriação do conhecimento pela escola, o processo de transposição didática que retira do conceito sua historicidade e sua problemática.

\section{PROCESSOS DE MEDIAÇÃO DIDÁTICA}

Neste trabalho, defendemos que o termo transposição didática não representa bem o processo ao qual nos referimos: (re)construção de saberes na instituição escolar. O termo transposição tende a ser associado à idéia de reprodução, movimento de transportar de um lugar a outro, sem alterações. Mais coerentemente, devemo-nos referir a um processo de mediação didática. Todavia, não no sentido genérico, ação de relacionar duas ou mais coisas, de servir de intermediário ou "ponte", de permitir a passagem de uma coisa a outra. Mas no sentido dialético: processo de constituição de uma realidade através de mediações contraditórias, de relações complexas, não imediatas, com um profundo sentido de dialogia.

Na Química, um exemplo que caracteriza esse processo claramente é o tratamento conferido à estrutura atômica. Os princípios da Mecânica Quântica passam a ser discutidos no ensino brasileiro a partir da década de 50, como uma das conseqüências do processo de inovação educacional do ensino de ciências ocorrido no pós-guerra que, entre outros aspectos, divulgou no país os projetos americanos para o ensino de Ciências ${ }^{8}$. A apropriação de conceitos como orbital ou de princípios como o de Heisenberg, feita por livros didáticos, banalizou-os de tal modo que assumiram significados completamente díspares em relação aos originais ${ }^{9}$. A Mecânica Quântica, que originalmente rompe com concepções realistas da ciência e estabelece uma descontinuidade com o mundo macroscópico, é transmitida como essencialmente realista e esquemática. O processo de distribuição eletrônica, que possui um significado fundamental para compreensão da estrutura molecular, passa a ser considerado no ensino médio como uma espécie de jogo: conhecidas as regras de preenchimento dos orbitais, nada mais fácil do que neles "colocar" os elétrons.

As razões para tal processo de didatização se aproximam daquelas apontadas por Chevallard e Johsua quanto ao conceito de distância. Ensinamos apenas o resultado, não o processo histórico de construção do conceito, portanto, retiramo-lo do conjunto de problemas e questões que o originaram. Por outro lado, existe uma tendência didática, melhor dizendo, um didatismo, que considera necessário chegar ao abstrato a partir do concreto, a fim de se tornar um conceito assimilável, o que só reforça a continuidade com o senso comum. Desta forma, ao invés de construirmos modelos de compreensão da racionalidade científica, tentamos aproximar os conceitos científicos da racionalidade do senso comum, incorporando-os em uma matriz eminentemente realista e empirista. Como a ciência se constrói em rompimento com o senso comum cotidiano ${ }^{10}$, fatalmente incorremos em distorções do conhecimento científico. Tais distorções, de uma maneira geral, estão associadas à utilização de um sem-número de metáforas e analogias.

\section{METÁFORAS E ANALOGIAS}

No caso da Química, os processos de mediação didática voltados para a aproximação com o senso comum se fazem normalmente pelo uso de metáforas realistas, constituintes de obstáculos epistemológicos e pedagógicos ${ }^{11}$. A proliferação destes obstáculos no ensino de Química de nível médio tende a produzir um hiato entre a comunidade científica e a comunidade escolar e não efetiva aprendizagem científica ${ }^{12}$. Todavia, suplantar o uso equivocado de metáforas no ensino de ciências não é de modo algum tarefa simples, destituída de questões importantes a serem aprofundadas.

Em artigo de revisão, Duit ${ }^{13}$ analisa o papel das analogias e metáforas no ensino de ciências. A partir de uma perspectiva construtivista $^{14}$, o autor defende que as analogias podem ser valiosas ferramentas no ensino por mudança conceitual, caso seus aspectos metafóricos sejam devidamente considerados. Com essa premissa, já podemos observar a existência de uma diferenciação entre os termos analogia e metáfora. Analogia é definida por Duit como comparação de estruturas entre dois domínios; simples comparações com base em similaridades superficiais não são por ele consideradas analogias. Ou seja, deve existir uma identidade profunda entre partes das estruturas. Metáforas, diferentemente, são comparações nas quais sua base deve ser revelada ou mesmo criada pelo destinatário da metáfora. Trata-se de uma comparação implícita, que privilegia qualidades não coincidentes nos dois domínios (Ex: O professor é o capitão do navio).

Em outra palavras, analogias devem tornar uma nova informação mais concreta e fácil de imaginar, de visualizar, e são, reconhecidamente, utilizadas com freqüência no cotidiano por todos nós. Por compreender que o processo de ensino-aprendizagem tem por objetivo transformar o não-familiar em familiar e construir familiaridades entre o já conhecido e o desconhecido, Duit considera o uso de analogias fundamental em uma perspectiva construtivista de ensino.

Por outro lado, para Duit, as metáforas são uma possível forma de produzir uma anomalia capaz de provocar um conflito cognitivo. Assim, analogias se diferenciam das metáforas em um pequeno grau. Toda boa analogia possui um certo aspecto metafórico de surpresa, o que lhe confere sua característica como boa ferramenta de ensino. Ou seja, o aspecto metafórico das analogias lhes confere a capacidade de motivar os alunos. Por isso, segundo Duit, os professores muitas vezes devem partir das metáforas para as analogias.

Dentre as desvantagens e potenciais perigos das analogias, Duit aponta para os seguintes aspectos: 1) como nunca existe equivalência absoluta entre a analogia e o objeto alvo, as diferenças entre os mesmos podem ser fonte de enganos; 2) o raciocínio analógico pressupõe um bom conhecimento da analogia, pois o que for compreendido incorretamente na analogia será transferido para o objeto alvo também incorretamente; 3 ) apesar das analogias serem muito freqüentes no cotidiano, o uso de analogias no ensino nunca é espontâneo; exige considerável orientação.

Duit aponta que analogias e metáforas servem de forma significativa ao desenvolvimento da ciência, cumprindo funções explanatória e heurística. Assim sendo, se considerarmos que a escola deveria ensinar não apenas o conhecimento científico, mas também o metaconhecimento científico, as analogias e metáforas assumem papel fundamental no ensino de ciências.

A limitação central da análise de Duit é o fato de não problematizar o processo de, através das metáforas e analogias, haver o objetivo de tornar o conhecimento científico próximo, familiar. Sem dúvida, a assimilação do conhecimento científico 
passa pela superação do distanciamento e do desconforto com concepções tão distantes do senso comum. Contudo, se essa aproximação entre concepções científicas e concepções cotidianas for feita indiscriminadamente, corremos o risco de reforçar o continuísmo e impedir que o aluno compreenda as diferenças imensas entre os conceitos nestes dois contextos. Em outras palavras, com a utilização de metáforas e analogias familiares, negamos que o aprendizado das ciências exige necessariamente o estranhamento, a percepção do inusitado e da não-familiaridade, a fim de se compreender concepções e conceitos que não fazem parte do senso comum. Ao contrário, invariavelmente, quando os alunos utilizam metáforas e analogias o fazem com o intuito de reforçarem suas concepções cotidianas e espontâneas que, de uma maneira geral, precisam ser desconstruídas pelos professores no processo de ensino-aprendizagem.

Um dos aspectos não analisados por Duit é o papel das metáforas e analogias na ciência, o que é focalizado com precisão por Nersessian ${ }^{15}$. A autora argumenta que as atividades cognitivas dos cientistas construtores de novas estruturas conceituais são especialmente relevantes para o ensino. Através da compreensão destas práticas, podemos ver facilitados nossos esforços em ajudar os estudantes a construírem representações do conhecimento científico atual. Isso porque a autora conclui haver semelhança entre os processos cognitivos das históricas revoluções científicas e da aprendizagem por mudança conceitual.

Sua análise tem por eixo central a constatação de que, através da história da ciência, as "técnicas de abstração", tais como: analogias, imagens, ou experimentos de pensamento, têm papel central tanto na construção de novas representações científicas, quanto nas comunicações destas aos membros da comunidade científica. Para Nersessian, não existe conflito inerente entre a interpretação dos processos de descoberta científica como criativos e como racionais. Ademais, a autora tem em vista que novas estruturas conceituais não emergem gratuitamente nas mentes dos cientistas, mas são construídas em resposta a problemas específicos, através da utilização de procedimentos sistemáticos.

O exemplo histórico analisado para corroborar essas conclusões é o processo de elaboração da teoria do eletromagnetismo de Maxwell, a partir das representações de campos de força de Faraday. Através do estudo de Nersessian, constatamos o quanto as representações imagéticas de Faraday, bem como analogias entre o eletromagnetismo e a mecânica contínua, foram fundamentais para Maxwell matematizar o eletromagnetismo ${ }^{16}$. Suas conclusões são de que as práticas construtivas dos cientistas incluem simulações de construções mentais, criação de representações externas pictóricas, bem como construção e manipulação de modelos analógicos. Para a autora, todas estas técnicas envolvem um processo de abstração dos fenômenos ou representações existentes, além da criação de um modelo esquemático e idealizado para racionalizar e quantificar.

Se queremos ensinar ciências efetivamente, precisamos, então, segundo Nersessian, começar por ensinar aos professores verdadeiramente como são os processos de construção das teorias científicas, pois aprender ciência pressupõe engajamento nas autênticas práticas científicas.

Contudo, precisamos analisar que a semelhança, defendida pela autora, entre os processos cognitivos das históricas revoluções científicas e da aprendizagem por mudança conceitual parece ser representativa de uma visão continuísta da história da ciência. A idéia de que o passado explica o presente, pois este é fruto da contínua elaboração daquele, embasa a perspectiva de que a história da ciência é capaz de nos ajudar a compreender os processos educacionais de hoje. Nesse caso, omite-se o aspecto recorrente da história, analisado por Bachelard: interpretamos o passado com os princípios do presente, efetuando sempre uma história judicativa ${ }^{17}$. Por outro lado, admitir que nossos alunos hoje interpretam a ciência com elementos semelhantes aos utilizados pelos cientistas no passado é considerar uma pequena diversidade nos processos de construção do conhecimento científico. Isso nos faz pensar na necessidade de um extremo cuidado na admissão de tal paralelismo ${ }^{18}$.

Tais considerações não visam desmerecer, entretanto, o papel fundamental que a história das ciências tem a exercer no ensino. A história das ciências não só fornece elementos que permitem compreender mais claramente os conceitos científicos, como também permite questionar a visão do senso comum acerca do conhecimento científico enquanto um conhecimento derivado da experiência e da observação imediata. Além de desconstruir a idéia de ciência como um conhecimento acabado, definitivo, restrito aos iluminados.

Podemos perceber que, para Nersessian, o uso de metáforas e analogias não tem a função de facilitar o processo de ensinoaprendizagem por aproximar o conhecimento científico da familiaridade do aluno, como aponta Duit. As técnicas de abstração são importantes no ensino por serem entendidas como a base da construção do próprio conhecimento científico.

Em nossa interpretação, portanto, enquanto Duit desconsidera o significado epistemológico desse processo de aproximar o não-familiar ao familiar, Nersessian analisa a utilização de metáforas e analogias no ensino no mesmo nível que na ciência. A autora não tem por fim analisar o processo de mediação didática que as descontextualiza.

Devemos, assim, acrescentar que, nas ciências físicas, o uso da metáfora é muito bem situado; existe como forma de expressão de conceitos inicialmente construídos a partir de uma linguagem formal. A linguagem matemática possui nas ciências um caráter fundamentante, constituidor de teorias, e a expressão em linguagem não formal, necessária para a comunicação de resultados e explicações, se utiliza de metáforas para conseguir expressar os novos conceitos criados pela linguagem formal.

É o caso, por exemplo, do conceito de orbital. No campo da Física Quântica, orbital é concebido como a resposta da resolução de uma função de onda para um elétron. Porém, esse conceito em Química não é operacional, não permite a construção das teorias de estrutura atômica e molecular fundamentais para essa ciência. Assim, de forma bastante coerente com o que Bachelard denomina racionalismos setoriais ${ }^{19}$ os químicos trabalham em seu campo com o conceito de orbital como região do espaço em que existe maior probabilidade de se encontrar um elétron.

Portanto, enquanto o uso da metáfora não perde de vista seu processo de construção - sua estreita ligação com a linguagem formal -, não se constitui enquanto obstáculo epistemológico. Todavia, sempre que o uso da metáfora é feito para que não enfrentemos os raciocínios formais ou, ainda mais problemático, sempre que o uso da metáfora é feito sem que a consideremos como tal, incorremos em sérios problemas epistemológicos. Freqüentemente, constatamos isso no ensino: a banalização da metáfora e da analogia como forma de marcar o continuísmo entre conhecimento comum e conhecimento científico. Não se trata do uso de "técnicas de abstração", em estreita relação com os processos racionais, como descreve Nersessian. Mas do uso de imagens de forma a estabelecer um didatismo anti-científico.

Contudo, tendemos a concordar com Astolfi e Develay ${ }^{20}$ quando afirmam que não é característica inerente à escola transmitir conhecimentos que sejam obstáculos à construção do conhecimento científico ou que necessariamente contenham erros em função de um processo de mediação didática.

Pois a escola nunca ensinou saberes ('em estado puro' é o que se desejaria dizer), mas sim conteúdos de ensino que resultam de cruzamentos complexos, um projeto de formação e exigências didáticas. Deste ponto de vista, as transformações sofridas na escola pelo saber sábio devem ser interpretadas menos em termo de desvio ou de degradação sempre em geração (ainda que isto exista, como vimos 
anteriormente), do que em termos de necessidade constitutiva, devendo ser analisada como tal. Pois, reunindo um currículo, todo conceito científico se integra numa nova economia do saber: ele deve e pode designar alguma coisa que possa ser aprendida (um "texto do saber", diria Chevallard), deve abrir um campo de exercícios para produzir ou permitir conceber sessões de trabalhos práticos... E também características e exigências que não existiam no contexto do saber sábio.

Por vezes, podemos constatar que o esforço de professores e livros didáticos em elaborar explicações para seus alunos com o uso da linguagem não formal acaba por constituir novas formas de abordagem de conceitos científicos, novas configurações cognitivas, não necessariamente equivocadas ou permeadas por obstáculos epistemológicos. Ao contrário, são formas que facilitam a compreensão de conceitos, inclusive pela comunidade científica. A investigação precisa destas novas formas de abordagem dos conceitos no ensino da Química é, portanto, um campo de pesquisa ainda não explorado e que certamente pode trazer contribuições fundamentais para a compreensão do conhecimento escolar e dos processos de ensino-aprendizagem.

Por outro lado, permanece como desafio, justamente, compreender o que parece ser, numa análise primeira, contradição intrínseca ao conhecimento escolar: ao mesmo tempo produzir configurações cognitivas próprias e socializar o conhecimento científico. Afinal, na maior parte das vezes, as configurações cognitivas da escola, o processo de mediação didática, têm distorcido o conhecimento científico, ao veicularem erros conceituais e visões de ciência conservadoras e equivocadas. Se aprofundarmos ainda mais essa análise, percebemos que essa contradição se acirra: a escola simultaneamente é uma instituição de veiculação do conhecimento científico, mediado pelo conhecimento escolar, e uma instituição de veiculação do saber cotidiano e de constituição do habitus ${ }^{21}$ que a sociedade seleciona para as gerações mais novas. E mais: esse saber selecionado pela sociedade é essencialmente um saber de classe, capaz de privar as classes exploradas de seu saber, o saber que expressa e se deriva de suas necessidades, de forma a substituí-lo por um saber portador das necessidades e dos interesses de outras classes. Essa contradição está diretamente associada ao papel da escola reproduzindo e produzindo, mantendo e renovando, mascarando e gerando rupturas ${ }^{22}$.

\section{CONCLUSÕES}

Em resumo, a escola tem o objetivo explícito de ministrar uma formação científica, ao mesmo tempo que possui o objetivo implícito de formar o conhecimento cotidiano, fazer com que o aluno incorpore cotidianamente, não apenas conhecimentos científicos, mas valores e princípios de uma dada sociedade.

A interpretação desse processo contraditório pode redundar em duas posições distintas, ambas, em nosso ponto de vista, questionáveis: a) a escola não tem como superar essa contradição, pois o conhecimento científico em si apresenta uma dificuldade superável apenas pela via da simplificação e, por conseguinte, da distorção de conceitos, cabendo apenas às instituições eminentemente produtoras de conhecimento o trabalho de veiculação do mesmo de forma correta; b) a única forma de superar essa contradição é resgatar na escola seu papel de transmissora / reprodutora de conhecimentos produzidos em outras instâncias, evitando a mediação didática.

Os equívocos da primeira interpretação se situam tanto na forma de enfrentamento da dificuldade do conhecimento, quanto na limitação de que camadas mais amplas da sociedade possam ter acesso a esse mesmo conhecimento. De acordo com essa perspectiva, contribuímos para a manutenção do conhecimento científico em circuitos privados e impedimos sua socialização. Afinal, o conhecimento científico é difícil, justamente, porque rompe com as concepções do conhecimento cotidiano, mas sua dificuldade não é intransponível, uma vez que é essencialmente uma produção humana. Um dos objetivos do trabalho de pesquisa em ensino de ciências deve ser o de elaborar estratégias e metodologias de ensino que visem entender por que o aluno não compreende. Compreender o ensino de ciências apenas pela via da vulgarização científica, além de não permitir a compreensão da ciência, só contribui para enfatizar seu caráter mítico. Fundamentalmente, por reforçar seu caráter de espetáculo, capaz de induzir ao culto e à admiração, mas não à reflexão.

$\mathrm{Na}$ segunda interpretação, igualmente negamos o dinamismo do conhecimento e dos atores sociais capazes de dialogar com esse mesmo conhecimento. Um diálogo que se faz não apenas através do consumo de um produto previamente elaborado, mas pela sua (re)construção. Portanto, devemos relativizar as instâncias de produção e consumo: o produtor também consome, na medida em que se insere em uma comunidade científica onde o conhecimento deve ser socializado; o consumidor também produz, na medida em que (re)elabora e (re)constrói o conhecimento para torná-lo compreensível a si e aos outros.

Como analisa Marx $^{23}$, no processo de produzir consumimos os meios de produção e as faculdades dos indivíduos. A produção, ao mesmo tempo que cria o objeto, cria o sujeito para o objeto. Isso porque lhe fornece o produto, determina o modo de consumo do produto e cria no consumidor a necessidade do produto. Por outro lado, consumo também é produção, na medida em que o ato de consumir produz novos objetos e/ou novas significações. Só no consumo, o produto se revela realmente como produto; adquire seu fundamento. Como, por sua vez, sem a necessidade não há produção, o consumo engendra a produção, a partir da reprodução da necessidade. Por isso, consumo não apenas é imediatamente produção e produção é imediatamente consumo; nem cada um é apenas o intermediário do outro: cada um, ao realizar-se, cria o outro; cria-se sob a forma do outro ${ }^{24}$.

A mediação didática não deve, por conseguinte, ser interpretada como um mal necessário ou como um defeito a ser suplantado. A didatização não é meramente um processo de vulgarização ou adaptação de um conhecimento produzido em outras instâncias (universidades e centros de pesquisa). Cabe à escola o papel de tornar acessível um conhecimento para que possa ser transmitido. Contudo, isso não lhe confere a característica de instância meramente reprodutora de conhecimentos. O trabalho de didatização acaba por implicar, necessariamente, uma atividade de produção original. Por conseguinte, devemos recusar a imagem passiva da escola como receptáculo de subprodutos culturais da sociedade. Ao contrário, devemos resgatar e salientar o papel da escola como socializadora / produtora de conhecimentos.

Afinal, essa é, acima de tudo, a função da escola: outras instâncias também podem trabalhar nesse mesmo sentido, notadamente os meios de comunicação de massa, mas nenhuma o fará tão bem quanto a escola, porque a nenhuma instituição a sociedade confere tão claramente esse poder.

\section{REFERÊNCIAS}

1. O material de pesquisa deste artigo foi apresentado, sob a forma de painel, na 19a Reunião Anual da SBQ, em maio de 1996. Tanto o painel quanto este artigo foram extraídos da tese de doutorado Conhecimento escolar: quando as ciências se transformam em disciplinas, defendida em julho de 1996, na Faculdade de Educação da UFRJ, sob orientação do Prof. Antonio Flavio Barbosa Moreira.

2. Warde afirma, em sua pesquisa sobre a pós-graduação em Educação no Brasil, que o grupo temático Temas Pedagógicos (o qual inclui a área de Ensino de Ciências) foi um dos mais significativos, do ponto de vista quantitativo, na produção de teses e dissertações, com um índice de 25,2 \% sobre o total da produção de 1982 a 1991. Ainda mais 
significativamente, as produções sobre "Ensino de ..." apresentaram o maior índice de crescimento $(108,3 \%)$ de 1987 a 1991, em relação ao período anterior (1982-1986), índice muito superior ao crescimento do grupo temático como um todo $(46,2 \%)$. Warde, M. A produção discente dos programas de pós-graduação no Brasil 1982 a 1991: avaliação e perspectivas. In: "Avaliação e perspectivas da pesquisa em educação". Relatório da ANPEd, 1993, p. 51-82.

3. A partir dos anais do VIII ENEQ / VIII ECODECQ, podemos constatar a diversidade de temas e de perspectivas teórico-metodológicas das pesquisas em Ensino de Química e Ensino de Ciências, bem como o amadurecimento teórico da área como um todo.

4. Forquin, J-C.; "Escola e cultura", Artes Médicas; Porto Alegre, 1993.

5. Chevallard, Y.; Johsua, M-A. Recherches en Didactique des Mathematiques. 1982, 1, p. 159-239.

6. Nesse sentido, os membros da Sociedade Brasileira de Química, especialmente os participantes da Divisão de Ensino e dos Encontros Nacionais e Regionais de Ensino de Química e das Revistas Química Nova e Química Nova na Escola, são integrantes da noosfera do ensino de Química.

7. Astolfi, J. P.; Develay, M. "La Didactique des Sciences"; Presses Universitaires de France; Paris, 1989.

8. Sobre o processo de inovação educacional no ensino de ciências ver: Krasilchik, M. Inovação no Ensino das Ciências. In: Garcia, W. (org.). "Inovação Educacional no Brasil - problemas e perspectivas", Cortez / Autores Associados; São Paulo, 1989, p. 164-180.

9. Lopes, A. R. C.; "Livros didáticos: obstáculos ao aprendizado da ciência química"; dissertação de mestrado; IESAE/FGV; Rio de Janeiro, 1990. Lopes, A. R. C.; Quím. Nova, 1992, 15, p. 254-261. Lopes, A. R. C.; Rev. Bras. de Est. Ped. 1993, 74, p. 309-334

10. Aprofundamos a análise sobre a questão da ruptura conhecimento comum - conhecimento científico, na tese de doutorado (ver Ref. 1). Parte destas conclusões estão nos artigos: Lopes, A. R. C. ; Enseñanza de las Ciencias 1993, 11, p. 324-330 \& Lopes, A. R. C. Currículo e a construção do conhecimento na escola. In: Moreira, A. F. B. (org.) . Conhecimento Educacional e Formação do Professor; Papirus; Campinas, 1995, p. 39-52.

11. Obstáculos epistemológicos são obstáculos inerentes ao desenvolvimento do próprio conhecimento científico, que marcam a tendência de mascararmos as rupturas do conhecimento. Nesse sentido, podemos denominar os obstáculos epistemológicos de anti-rupturas, resistências da razão aos avanços e revoluções da própria racionalidade. Obstáculos pedagógicos estão associados aos entraves que impedem o professor de conhecer porque o aluno não aprende determinado assunto, quais as razões que o fazem resistir ao aprendizado de um dado conceito. Bachelard, G. "La Formation de l'Ésprit Scientifique"; J. Vrin; Paris 1947.

12. Ref. 9.

13. Duit, R.; Science Education 1991, 75, p. 649-672.

14. A argumentação favorável ao uso de metáforas e analogias no ensino não é exclusiva de uma perspectiva construtivista, mas os autores construtivistas se dividem entre os que evitam a explicitação das idéias prévias dos alunos, preferindo a utilização de analogias para servirem como pontes entre intuições corretas dos alunos e situações análogas a serem aprendidas, e os que defendem a associação das analogias ao levantamento das concepções prévias. Duit se enquadra neste último grupo. Para maiores desenvolvimentos das relações entre o uso de analogias e as perspectivas construtivistas, ver: Mortimer, E. "Evolução do atomismo em sala de aula: mudança de perfis conceituais". tese de doutorado. Faculdade de Educação, USP, São Paulo 1994, p. 22-26.
15. Nersessian, N. Constructing and instructing: the role of "abstraction techniques" in creating and learning physics. In: Duschl, R. A.; Hamilton, R. J. (ed.). "Philosophy of science, cognitive psichology, and educational theory and practice". State University of New York; New York 1992, p. 48-68. How do scientists think ? Capturing the dynamics of conceptual change in science. In: Giere, R. (ed.). "Cognitive models of science" (Minnesota Studies in the Philosophy of Science, v. 15); University of Minnesota Press, Minneapolis, 1992. Science and Education 1995, 4, p. 203-226.

16. A análise das instigantes conclusões de Nersessian sobre os trabalhos de Maxwell merecem todo um trabalho à parte em história das ciências, o que não é objeto deste artigo. Deixamos apenas como observação, para futuras pesquisas, a necessidade de confrontarmos sua análise com colocações como a de Mario Schenberg, ao relatar a famosa conclusão de Hertz, um marco de interpretação nahistória da física, segundo a qual a teoria de Maxwell se consistia simplesmente das equações de Maxwell, em nada interessando o modelo mecânico que ele utilizara para formulá-las (Schenberg, M. "Pensando a Física"; Brasiliense; São Paulo, 1985, p. 85).

17. A noção de recorrência histórica em Bachelard é um dos aspectos que marca a descontinuidade do conhecimento científico por ele defendida. Segundo o epistemólogo francês, o historiador da ciência deve conhecer o presente para julgar o passado, é a partir dos valores do presente que podemos julgar o passado. Nesse sentido, a marca da ruptura está no fato de que o passado não é compreendido como uma preparação para o presente. Bachelard, G.; "L'Engagement Rationaliste", Presses Universitaires de France; Paris 1972.

18. Discussão análoga, com base nas concepções de Thomas Kuhn, são desenvolvidas em: Bizzo, N. M. V. Em Aberto. 1992, 11, p. 29-34.

19. Bachelard analisa que duas teorias científicas podem pertencer a dois corpos de racionalidades distintas, e ainda que essas racionalidades se oponham em determinados pontos, as teorias permanecem válidas em seu próprio corpo de racionalidade. Essa tese ele denomina racionalismos setoriais; trata-se de uma das fortes marcas da perspectiva pluralista de sua epistemologia. Bachelard, G. "La Philosophie du Non"; Presses Universistaires de France; Paris 1983.

20. Ref. 7.

21. Para Bourdieu, habitus é definido como sistema de disposições duráveis, estruturas estruturadas predispostas a funcionarem como estruturas estruturantes, isto é, como princípio que gera e estrutura as práticas e as representações que podem ser objetivamente 'regulamentadas' $e$ 'reguladas' sem que por isso sejam o produto de obediência de regras, objetivamente adaptadas a um fim, sem que se tenha necessidade da projeção consciente deste fim ou do domínio das operações para atingi-lo, mas sendo, ao mesmo tempo, coletivamente orquestradas sem serem o produto da ação organizadora de um maestro. (Bourdieu, citado por Ortiz, R. A procura de uma sociologia da prática. In: Bourdieu, P. "Sociologia". Introdução e organização de Renato Ortiz; Ática; São Paulo, 1983, p. 15). Nesse sentido, o habitus se constitui de um conjunto de valores, formas de percepção dominantes, incorporadas pelo indivíduo, e através dos quais ele percebe o mundo social, percepção que, por sua vez, regula sua prática social.. O habitus é sempre e unicamente uma internalização, consciente ou não, não tem existência exterior. O que tem existência exterior é a estrutura social, do qual ele é expressão exteriorizada.

22. Para uma discussão bastante clara e consistente do duplo papel da Educação enquanto produtora e reprodutora, ver: 
Silva, T. T. "O que produz e o que reproduz na educação”; Artes Médicas; Porto Alegre, 1992.

23. Marx, K. Introdução à Crítica da Economia Política. In:
"Contribuição à Crítica da Economia Política; Martins Fontes; São Paulo, 1977, p. 208-212.

24. Ref. 23, p. 211. 